\title{
Application of ultrasound-guided percutaneus neuromodulation (PNM) in women with anterior knee pain
}

\author{
García-Bermejo P. ${ }^{1}$ Albornoz-Cabello M. ${ }^{2}$ De la Cruz-Torres B. ${ }^{2}$ \\ ${ }^{1}$ DINAMIA Fisioterapia, Alcalá de Henares, Madrid, Spain \\ 2 Department of Physiotherapy, Universidad de Sevilla, Sevilla, Spain \\ Rev Fisioter Invasiva 2019;2:72.
}

\begin{abstract}
Keywords

- Ultrasound-Guided Percutaneous Neuromodulation

- anterior knee pain

- woman

Background Anterior knee pain (AKP) is one of the most common pathologies of the lower limb, with an incidence that is $2.2 \%$ greater in women than in men. Electric currents have been used as an effective treatment for pain in many pathologies, however, the percutaneous application of the same has represented a particularly great advancement. In the field of physical therapy, ultrasound-guided percutaneous neuromodulation (US-guided PNM), is a technique that is being developed with promising results, however there is still a scarcity of studies concerning this technique.

Aim To evaluate the improvement in chronic anterior knee pain symptoms after the application of US-guided PNM on the femoral nerve of the affected side or the healthy side, in a population of women.

Material and Methods The sample comprised 15 women with chronic unilateral AKP, who were randomly divided into two groups: experimental group $1(n=8)$, who received US-guided PNM upon the femoral nerve, on the leg of the affected side, and an experimental group $2(n=7)$, who received US-guided PNM on the femoral nerve of the non-affected side. The intervention was performed using a needle measuring $0.3 \times 40 \mathrm{~mm}$ on the motor fibers of the femoral nerve under ultrasound guidance and using a monopolar electrode, with a frequency of $10 \mathrm{~Hz}$ and a phase duration of 250 microseconds, during 1.5 minutes. We registered active ROM in both knees, pain according to the Visual Analog Scale (VAS) and functionality using the VISA-P questionnaire and the Kujala scale. All variables were evaluated pre-intervention, post-intervention and after 24 hours.

Results No statistically significant differences were found in both groups between the pre and post intervention measurements. However, statistically significant changes were found in both groups between the pre and post intervention at 24 hours, regarding increased ROM and functionality and a decrease in pain $(p<0.05)$. Nonetheless, the between-group comparison did not obtain a significant difference in any of the variables studied $(p>0.05)$. The measurement of the effect size obtained a large clinical effect between both groups and between the pre-intervention measurement and the assessment at 24 hours.

Conclusion Treatment of chronic AKP in women, using US-guided PNM, leads to an improvement of symptoms and functionality, 24 hours after application of the same, regardless of whether it is applied on the femoral nerve of the affected leg or on that of the healthy leg.
\end{abstract}

Copyright $\odot 2019$ by Thieme Revinter Publicações Ltda, Rio de Janeiro, Brazil
License terms

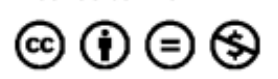

